\title{
Oligonucleotides Complementary to the Oxytricha nova Telomerase RNA Delineate the Template Domain and Uncover a Novel Mode of Primer Utilization
}

\author{
MENI MELEK, BRYAN T. DAVIS, AND DOROTHY E. SHIPPEN* \\ Department of Biochemistry and Biophysics, Texas A\&M University, \\ College Station, Texas 77843-2128
}

Received 7 July 1994/Returned for modification 25 August 1994/Accepted 14 September 1994

\begin{abstract}
The telomerase reverse transcriptase uses an essential RNA subunit as a template to direct telomeric DNA synthesis. The 190-nucleotide Oxytricha nova telomerase RNA was identified by using an oligonucleotide probe complementary to the predicted CCCCAAAA template. This RNA displays extensive sequence similarity to the Euplotes crassus telomerase RNA and carries the same 5' CAAAACCCCAAAACC 3 ' telomeric domain. Antisense oligonucleotides were used to map the boundaries of the functional template and to investigate the mechanism of primer recognition and elongation. On the basis of their ability to inhibit or to prime telomerase, oligonucleotides were classified into three categories. Category 1 oligonucleotides, which extended 5' of residue 42 in the RNA, abolished elongation of $\left(T_{4} G_{4}\right)_{3}$ and $\left(G_{4} T_{4}\right)_{3}$ primers in vitro. In contrast, oligonucleotides terminating between residues 42 and 50 (categories 2 and 3), served as efficient telomerase primers. We conclude that the $O$. nova template comprises residues 42 to 50 in the 190-nucleotide RNA, a different set of nucleotides than are used by the $E$. crassus enzyme. Category 2 primer reactions amassed short products, and their abundance could be decreased by altering the $5^{\prime}$ sequence of the primer, consistent with the two-primer-binding-site model for telomerase. Category 3 primers generated a bimodal distribution of short and long products, each having a unique elongation profile. The long-product profile is inconsistent with sequence-specific primer alignment. Rather, each primer was extended by the same register of TTTTGGGG repeats, suggesting shuttling to a default position within the template. The parallels between telomerase and RNA polymerase elongation mechanisms are discussed.
\end{abstract}

A special mechanism is needed to maintain the ends of eukaryotic chromosomes (45). In many organisms, telomerase catalyzes the addition of telomeric DNA onto chromosomes de novo, thereby replenishing terminal sequences that are lost during conventional DNA replication (reviewed in references 6 and 41). Telomerase is an unusual ribonucleoprotein (RNP) reverse transcriptase with essential RNA and protein subunits. Telomerase activity has been characterized from a variety of sources, including several ciliated protozoa, mice, humans, and most recently amphibians $(17,23,29,35,43,49)$. The ubiquity of telomerase activities reflects the conserved structure of telomeric DNA, which in most eukaryotes consists of short reiterative sequence arrays, with clustered $G$ residues on the strand that runs $5^{\prime}$ to $3^{\prime}$ toward the chromosome end (reviewed in reference 50 ).

Both processive and nonprocessive telomerases have been reported $(16,27,35)$, but in all cases, a single-stranded G-rich primer resembling the natural extension on the telomere is needed for efficient elongation in vitro $(17,23,29,35,43,49)$. Telomerase has been postulated to contain two primer binding sites $(9,19,22,23,30)$ : one within the RNA subunit called the template site, and a second anchor site, possibly located within an undefined protein component (9). In addition to polymerase activity, the Tetrahymena thermophila telomerase carries a 3 '-to-5' nucleolytic cleavage activity that may serve to aid primer elongation (9). The sequence of DNA added by telomerase is determined by a template within the RNA subunit $(1,18,44,48)$. The Tetrahymena telomerase RNA, for example, bears the sequence 5' CAACCCCAA 3' (18). Site-

* Corresponding author. Phone: (409) 862-2342. Fax: (409) 8459274. Electronic mail address: DSHIPPEN@BIOCH.TAMU.EDU. directed mutagenesis of this domain showed that it is required to direct the synthesis of TTGGGG repeats both in vitro and in vivo $(1,48)$. The template can be divided into two functional domains; these comprise the nucleotides that align the primer or specify the sequence that will be added (1).

Besides the Tetrahymena RNA, the only other telomerase RNA molecule that has been analyzed biochemically is from the hypotrichous ciliate Euplotes crassus (44). As with the Tetrahymena enzyme, the Euplotes telomerase RNA carries a sequence that templates the addition of telomeric repeats, in this case 5' CAAAACCCCAAAACC 3'. In vitro experiments using oligonucleotides complementary to the E. crassus RNA indicated that up to 12 of the 15 nucleotides in this domain can be copied into DNA during the synthesis of TTTTGGGG repeats. Although the Tetrahymena and Euplotes RNAs can be folded into similar secondary structures $(23,25,38,40)$, the divergence of their nucleotide sequences has made the isolation of additional RNAs from outside these genera technically difficult.

Here we report the identification of the telomerase RNA subunit from the ciliate Oxytricha nova. We analyzed the $O$. nova telomerase for two reasons. First, the structure of the $O$. nova telomere complex has been studied in detail, including the identification of telomere-binding proteins and telomerase activity $(14,15,42,49)$. Second, although very distantly related to $E$. crassus (34), O. nova also carries the TTTTGGGG telomere repeat sequence (21). Thus, a comparison of the two telomerases was expected to be informative. In this report, we present an investigation of the $O$. nova telomere elongation mechanism, using oligonucleotides complementary to the telomerase RNA as inhibitors and primers for this enzyme. Remarkably, although the $O$. nova telomerase synthesizes the 
same telomeric sequence as $E$. crassus, different nucleotides in the RNA subunits appear to be used as the template.

\section{MATERIALS AND METHODS}

Isolation of macronuclei and macronuclear RNA and DNA. $O$. nova macronuclei containing active telomerase were isolated from Percoll-Nycodenz gradients as described previously (49) except that the nuclei were resuspended in TMG $(10 \mathrm{mM}$ Tris- $\mathrm{HCl}$ [pH 7.0], $1 \mathrm{mM} \mathrm{MgCl}, 10 \%$ glycerol) containing 5 $\mu \mathrm{M}$ phenylmethylsulfonyl fluoride (Boehringer), $7 \mu \mathrm{g}$ of pepstatin A (Boehringer) per $\mathrm{ml}$, and $40 \mathrm{U}$ of RNasin (Promega) per ml. RNA was prepared from cells or macronuclei by the acid guanidinium thiocyanate-phenol-chloroform extraction method (8), and DNA was purified by proteinase $\mathrm{K}$ digestion and phenol extraction (21).

RNA and DNA sequence analysis. For reverse transcriptase sequencing of the 190-nucleotide RNA (190 RNA), a $\left[\gamma^{32} \mathrm{P}\right]-$ 5 -end-labeled oligonucleotide complementary to the $E$. crassus telomerase RNA template, Eup 36-64 (5' CGCACCTAT TGATCGGGTTTTGGGGTTTTG $3^{\prime}$ ), was incubated with 25 $\mu \mathrm{g}$ of total $O$. nova RNA at $43^{\circ} \mathrm{C}$ and primer extended in the presence of dideoxynucleotides with $1 \mathrm{U}$ of avian myeloblastosis virus reverse transcriptase (Promega) for $1 \mathrm{~h} \mathrm{(32).}$ Reaction mixtures were treated with RNase A, phenol extracted, and ethanol precipitated. Samples were separated on an $8 \%$ sequencing gel and subjected to autoradiography.

For chemical sequencing of the 190 RNA, $10 \mu \mathrm{g}$ of macronuclear RNA was $3^{\prime}$ end labeled with $\left[{ }^{32} \mathrm{P}\right]$ cytidine $3^{\prime}, 5^{\prime}$ biphosphate (Amersham) and phage T4 RNA ligase (New England Biochemical) (13). The 190 RNA band was excised from a $12 \%$ denaturing polyacrylamide gel and eluted into TE (10 mM Tris- $\mathrm{HCl}$ [pH 7.5], $1 \mathrm{mM}$ EDTA) overnight at $37^{\circ} \mathrm{C}$. The 25-nucleotide sequence obtained was used to generate Oxy 5' and Oxy 5' PCR oligonucleotides (Fig. 1 and 2). Chemical cleavage sequencing reactions were performed as described previously (33), and 25 nucleotides of sequence data were used to synthesize the Oxy $3^{\prime}$ oligonucleotide (Fig. 2).

A SequiTherm Cycle sequencing kit (Epicenter Technologies) was employed for DNA sequence analysis using $\left[\alpha-{ }^{32} \mathrm{P}\right]$ dGTP (New England Nuclear).

RNase $H$ reactions and Northern (RNA) hybridization analysis. Telomerase was solubilized from macronuclei by potassium glutamate treatment (42) and incubated at $30^{\circ} \mathrm{C}$ for 45 min with $5 \mathrm{U}$ of RNase $\mathrm{H}$ (Promega), $2 \mu \mathrm{g}$ of oligonucleotide, and telomerase buffer (50 mM Tris- $\mathrm{HCl}$ [pH 8.0], $1 \mathrm{mM}$ spermidine, $1 \mathrm{mM}$ dithiothreitol). RNA from the reaction was resolved on a $6 \%$ denaturing gel and transferred to a $0.45-\mu \mathrm{m}-$ pore-size magnagraph membrane (Micron Separations, Inc.; Fisher) by electroblotting. The filter was hybridized with ${ }^{32}$ P-labeled Oxy tel PCR (a PCR product corresponding to the 190 RNA gene) in Rapid-hyb buffer (Amersham) according to the manufacturer's instructions. Northern hybridizations with oligonucleotide probes were carried out at $42^{\circ} \mathrm{C}$ overnight in $5 \times$ SSPE $\left(5 \mathrm{mM} \mathrm{Na}_{2}\right.$ EDTA, $40 \mathrm{mM} \mathrm{NaOH}, 50 \mathrm{mM}$ $\left.\mathrm{NaH}_{2} \mathrm{PO}_{4} \cdot \mathrm{H}_{2} \mathrm{O}, 0.9 \mathrm{M} \mathrm{NaCl}\right)-1 \times \mathrm{SPED}(0.1 \%$ polyvinylpropylene-360, $0.1 \%$ bovine serum albumin, $6 \mathrm{mM}$ sodium dodecyl sulfate [SDS], $2 \mathrm{mM}$ sodium pyrophosphate, $2 \mathrm{mM}$ $\mathrm{H}_{4}$ EDTA) (46) containing $5 \mathrm{mg}$ of torula RNA (ICN) per $\mathrm{ml}$. The filters were washed in $2 \times$ SSPE- $0.1 \%$ SDS at room temperature and then at $42^{\circ} \mathrm{C}$ for 15 min each time. Blots were then subjected to autoradiography.

Oligonucleotides for primers, markers, and probes. Oligonucleotides were obtained from the Texas A\&M Gene Technology laboratory and gel purified before use. For probes or telomerase reaction markers, the oligonucleotides were $5^{\prime}$ end labeled by using T4 polynucleotide kinase (Promega) and $\left[\gamma^{32} \mathrm{P}\right] \mathrm{dATP}$ (New England Nuclear). For some markers, the plus-one telomerase product was generated by labeling the oligonucleotide with terminal deoxynucleotidyltransferase (United States Biochemical) and $\left[\alpha-{ }^{32} \mathrm{P}\right] \mathrm{dGTP}$ or $\left[\alpha-{ }^{32} \mathrm{P}\right] \mathrm{TTP}$, depending on the primer. Following labeling, the plus-one product was eluted from a $20 \%$ denaturing gel as described above. Unless otherwise indicated, all of the antisense oligonucleotides were 21 nucleotides in length. The Oxy or Eup designation indicates an $O$. nova- or $E$. crassus-specific oligonucleotide, and the numbers correspond to residues within the $E$. crassus telomerase RNA sequence, as the complete sequence for the $O$. nova 190 RNA was not available.

PCR, PCR product probes, and cloning. Oxy tel PCR was generated by using a Perkin Elmer Cetus DNA Thermal Cycler in a reaction mixture that contained $0.2 \mu \mathrm{g}$ of $O$. nova macronuclear DNA, $1 \mu \mathrm{M}$ Oxy $5^{\prime}$ PCR (5' GGA(CTA)GTG CGTCAGTCATAGCACTG 3') and Oxy $3^{\prime}$ (5' AGAGAAA CTCTCAAATTTTCATTTC $3^{\prime}$ ) primers, $6 \mathrm{mM} \mathrm{MgCl}_{2}, 0.25$ $\mathrm{U}$ of Taq DNA polymerase (Promega), and $250 \mu \mathrm{M}$ deoxynucleoside triphosphates. Reaction mixtures were denatured at $94^{\circ} \mathrm{C}$ for $30 \mathrm{~s}$, annealed at $50^{\circ} \mathrm{C}$ for $30 \mathrm{~s}$, and elongated at $72^{\circ} \mathrm{C}$ for $1 \mathrm{~min}$ for 30 cycles. The 155 -nucleotide product was isolated from a 1\% low-melting-point agarose gel (FMC BioProducts). After phenol-chloroform extraction and ethanol precipitation, the PCR product was cloned into the SmaI polylinker site of pUC 119 and sequenced as described above. For probing Northern blots, ${ }^{32}$ P-labeled Oxy tel PCR was generated by using PCR (3) with Oxy $5^{\prime}$ and Oxy $3^{\prime}$ primers, with $\left[\alpha-{ }^{32} \mathrm{P}\right] \mathrm{dGTP}$ (New England Nuclear) as the label.

Telomerase assays. $O$. nova telomerase was solubilized from isolated macronuclei (42). Forty-microliter telomerase assay mixtures, containing $0.1 \mu \mathrm{g}$ of oligonucleotide primer (approximately $0.4 \mu \mathrm{M}$, final concentration) and reaction cocktail (10 $\mathrm{mM}$ Tris [pH 7.5], $100 \mu \mathrm{M}$ TTP, $1 \mu \mathrm{l}$ of $\left[\alpha^{-32} \mathrm{P}\right] \mathrm{dGTP}[800$ $\mathrm{Ci} / \mathrm{mM}$; New England Nuclear], $20 \mathrm{mM}$ EGTA, $1 \mathrm{mM}$ spermidine, $1 \mathrm{mM}$ dithiothreitol, $5 \mathrm{mM} \mathrm{MgCl}_{2}$ ) were incubated at $30^{\circ} \mathrm{C}$ for $1 \mathrm{~h}$ and then phenol extracted and ethanol precipitated (42). After resuspension in loading dye, samples were resolved on a $6 \%$ sequencing gel and subjected to autoradiography. For the blocking experiments, telomerase extracts were preincubated with $0.1 \mu \mathrm{g}$ of antisense oligonucleotide for 10 min at $30^{\circ} \mathrm{C}$, cocktail containing $0.1 \mu \mathrm{g}$ of either $\left(\mathrm{T}_{4} \mathrm{G}_{4}\right)_{3}$ or $\left(G_{4} T_{4}\right)_{3}$ was added, and the incubation was continued for $1 \mathrm{~h}$. Afterward, the reaction was processed as described above. Products shown in Fig. 7B were quantitated with a Betascope blot analyzer (Betagen).

\section{RESULTS}

Identification of a telomerase RNA candidate from $O$. nova. Two independent screens were undertaken to identify the telomerase RNA component from $O$. nova. Both approaches searched for an RNA bearing the sequence CCCCAAAA, the predicted template for this telomerase. First, an oligonucleotide complementary to the $E$. crassus telomerase RNA template domain was used for reverse transcriptase dideoxy sequencing on total $O$. nova macronuclear RNA. Twenty-five nucleotides of sequence data were obtained and used to synthesize an oligonucleotide probe (Oxy 5'). Oxy $5^{\prime}$ identified a macronuclear RNA species of approximately 190 nucleotides on a Northern blot (Fig. 1A).

In a second screen, a Northern blot of $O$. nova macronuclear RNA was probed with the ${ }^{32} \mathrm{P}$-labeled oligonucleotide, $\left(\mathrm{T}_{4} \mathrm{G}_{4}\right)_{3}$. Under relatively high stringency hybridization conditions, an RNA species of 190 nucleotides was observed (Fig. 
A

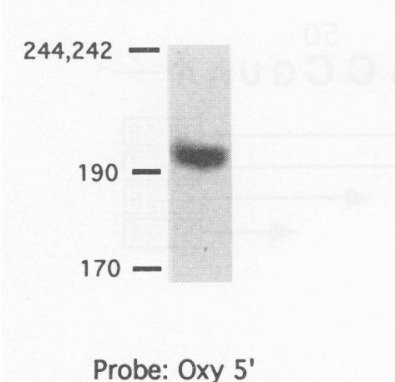

B

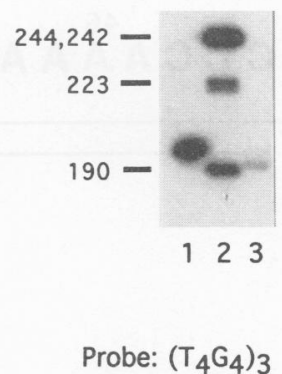

C

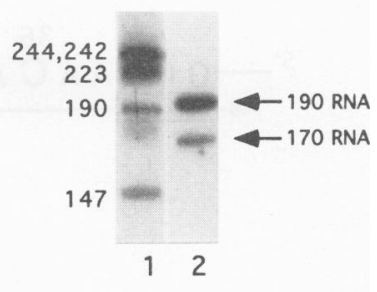

Probe: Oxy tel PCR

FIG. 1. Detection of a telomerase RNA candidate from $O$. nova by Northern blotting of total macronuclear RNA. Molecular weight standards (sizes indicated in nucleotides) and probes are as indicated. (A) Oxy 5' (5' CAGTGCTATGACTGACGCAC(GAT)TCC 3'). (B) Lane 1, T7 transcripts of the $E$. crassus telomerase RNA (47); lane $2,{ }^{32} \mathrm{P}$-labeled molecular weight standards; lane 3, $O$. nova macronuclear RNA. (C) Lane 1 , molecular weight standards; lane 2, $O$. nova macronuclear RNA.

1B, lane 3). Upon longer exposure, a second $O$. nova RNA of 170 nucleotides (170 RNA) was also detected (not shown). We used the direct chemical cleavage method to sequence the $3^{\prime}$ terminus of the 190 RNA. Although approximately 50 nucleotides of sequence data were obtained, the $5^{\prime}$-most 25 residues were least ambiguous of the data, and these were used to design the oligonucleotide probe (Oxy 3') (Fig. 2). Oxy 3' detected 190 and 170 RNAs on a Northern blot (not shown).

PCR was carried out with the oligonucleotides generated from the RNA sequence data as primers on $O$. nova macronuclear DNA. A product of 155 nucleotides, designated Oxy tel PCR, was generated. When Oxy tel PCR was used to probe a Northern blot, 170 and 190 RNAs were identified (Fig. 1C). Because the abundance of the 170 RNA varied with different RNA preparations, we postulate that it is a specific degradation product of the 190 RNA.

The 190 RNA displayed properties consistent with its being the $O$. nova telomerase RNA. First, like the $E$. crassus and $T$. thermophila telomerase RNAs $(2,44)$, the 190 RNA is abundant, with approximately $10^{6}$ RNA molecules per vegetative macronucleus, as determined by quantitative Northern blotting (not shown). Second, the 190 RNA sedimented as a highmolecular-weight complex in a glycerol gradient (4), suggesting that it was present in an RNP particle. Finally, the sequence of the Oxy tel PCR displayed several hallmarks of a telomerase RNA subunit (Fig. 2). Oxy tel PCR carries the same telomeric sequence as the $E$. crassus telomerase RNA, 5' CAAAACCC CAAAACC 3' (44). Moreover, immediately upstream of the telomeric domains in both molecules are the nucleotides GUCA; these residues are conserved among the 20 holotrichous ciliate telomerase RNAs sequenced to date $(25,37,38)$. Outside the putative template domain, the $O$. nova RNA exhibited several patches of sequence identity to the $E$. crassus RNA. Although Oxy tel PCR does not span the entire 190 RNA, we recently learned that the complete sequence for the $O$. nova telomerase RNA will soon be published along with a model for telomerase RNA secondary structure based phylogenetic comparison of several hypotrichous ciliate telomerase RNAs (25). Oxy tel PCR matches the $O$. nova telomerase RNA sequence, spanning positions 8 to 159 in the RNA (25).

oxy $5^{\prime}$

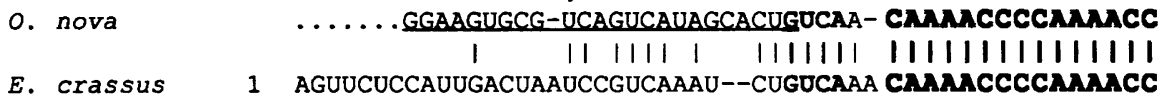

o. nova

E. crassus

GUAAACUCAGAGCAAUUCGCCUGGUU---CCUCUUUAAAGCAAAACCAGGAGGUU

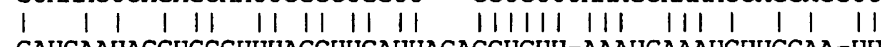
51 GAUCAAUAGGUGCGUUUAGCUUGAUUACACCUCUU-AAAUGAAAUCUUGCAA-UU

o. nova

O. nova CCGCC-AGCUACCAGAGGACGAAGUGG----GCUAAGUGAAAUGAAAAUUUGAGA I | |||| ||||| || | || || ||| | | ||||||| E. crassus 104 CUGGAGAGCUUG-AGAGGUGAAACCCCCACAGUUAGGUCAAA-CAUAGUUUGAGA
0. nova
E. crassus
$\frac{\text { GUUU--CUCU. }}{111} 111 \ldots \ldots \ldots \ldots \ldots \ldots \ldots$
- uuvguaucucauaugcucuagcuguccucucaucuu

FIG. 2. Alignment of the Oxy tel PCR product with the $E$. crassus telomerase RNA. The numbers to the left of the $E$. crassus sequence denote relative nucleotide positions (44). The transcriptional start site for the E. crassus RNA was mapped by primer extension (40). Oxy 5' and Oxy 3' oligonucleotide sequences determined by reverse transcriptase sequencing and direct chemical sequencing (see text) are underlined. The telomeric domains in both sequences are outlined, and the four conserved nucleotides upstream of the telomeric sequence are in boldface. Oxy tel PCR corresponds to the majority of the 190 RNA sequence; however, the complete sequence contains an additional 7 nucleotides at the $5^{\prime}$ terminus and 30 nucleotides at the $3^{\prime}$ terminus as designated by the dots (reference 25 and text). 

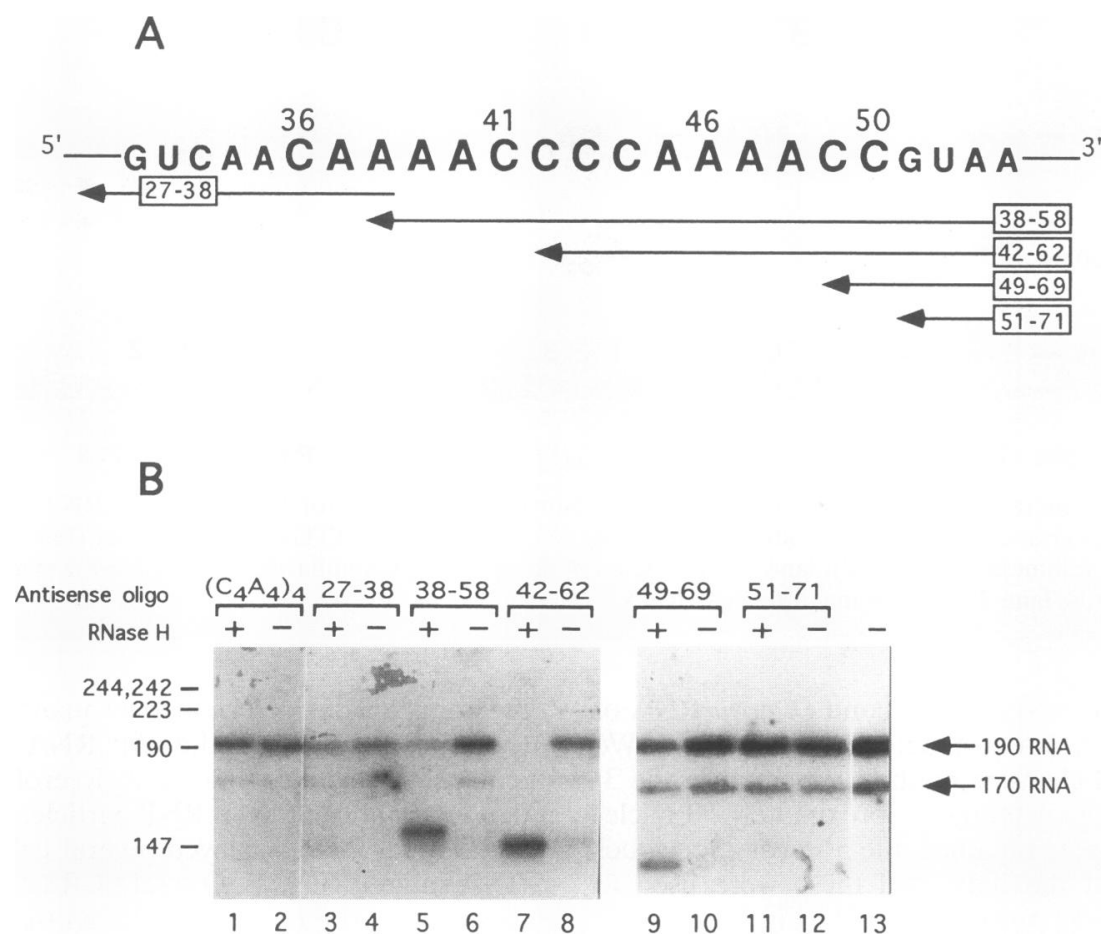

FIG. 3. Accessibility of the telomeric sequence within the 190 RNP particle to oligonucleotide-directed RNase H cleavage. (A) Antisense oligonucleotides used for RNase H cleavage. The telomeric sequence within the 190 RNA in boldface is numbered on the basis of the complete E. crassus telomerase RNA sequence (see text). The $3^{\prime}$ terminus of antisense oligonucleotides, shown below the RNA sequence, is indicated by the arrowhead. (B) Cleavage of the 190 RNA by RNase H. Following RNase H digestion, macronuclear RNA was isolated and subjected to Northern blotting using ${ }^{32}$ P-labeled Oxy tel PCR as a probe. Molecular weight standards (sizes in nucleotides) are indicated. Lane 13, untreated O. nova macronuclear RNA. The arrows denote the 190 RNA and the 170 RNA, which appears to be a specific breakdown product of the 190 RNA.

This positioning within the full-length molecule agrees with our $3^{\prime}$-terminal RNA sequence data. Therefore, we turned our attention to an investigation of the biochemical role of the $O$. nova 190 RNA in telomere synthesis.

In order for the 190 RNA to provide a template for telomerase, the telomeric sequence must be accessible within the RNP for base pairing to a DNA primer. We tested this prediction by assaying for oligonucleotide-directed cleavage of this domain within the native RNP by RNase $\mathrm{H}$, an enzyme that digests the RNA strand of RNA-DNA hybrids. The antisense oligonucleotide designations used in this report correspond to the positions within the 190 RNA where the oligonucleotides are expected to bind. Since a few of the nucleotides on the $5^{\prime}$ end of the $O$. nova 190 RNA were not known, and since this RNA displays extensive sequence homology with the $E$. crassus telomerase RNA, we numbered the $O$. nova telomeric sequence residues (and the antisense oligonucleotides) according to the full-length $E$. crassus sequence (44) (Fig. 2). Oxy 38-58, for example, spans much of the telomeric domain within the $O$. nova 190 RNA, its $3^{\prime}$ terminus binding to residue 38 within the putative template and its $5^{\prime}$ terminus extending to position 58 (Fig. 3A).

$O$. nova telomerase extracts were incubated with this and other antisense oligonucleotides in the presence or absence of RNase H, and the 190 RNA was examined by Northern blotting using Oxy tel PCR as a probe. Both the Oxy 38-58 and 42-62 oligonucleotides directed cleavage of the 190 RNA (Fig. 3B, lanes 5 and 7). The sizes of the largest digestion products agreed with those expected from the Oxy tel PCR sequence on the basis of its positioning within the complete telomerase 190
RNA (25) (Fig. 2). For example, cleavage with Oxy 38-58 was predicted to generate a fragment between 38 and 58 nucleotides (which would have run off the bottom of the gel) and a second product of between 122 and 152 nucleotides which corresponds to the $3^{\prime}$ portion of the RNA. As shown in Fig. 3B, lane 5 , a product of about 150 nucleotides was obtained. A slightly smaller fragment was observed with Oxy 42-62, consistent with hybridization of this oligonucleotide further $3^{\prime}$ within the RNA and its ability to generate a correspondingly smaller 3' RNA product (Fig. 3B, lane 7).

Oxy 27-38, an oligonucleotide that extends only a few nucleotides into telomeric sequence but covers the conserved GUCA just upstream, did not cause degradation of the 190 RNA (Fig. 3B, lane 3). Two oligonucleotides that bound $3^{\prime}$ of the telomeric domain, Oxy 51-71 and Oxy 49-69, behaved differently from each other even though their binding sites are offset by only two nucleotides. The 190 RNA was cleaved with Oxy 49-69 (Fig. 3B, 9) but not with Oxy 51-71 (Fig. 3B, lane 11). In control reactions containing deproteinized macronuclear RNA, both Oxy 49-69 and 51-71 directed cleavage of the 190 RNA (not shown). This finding is consistent with current telomerase RNA secondary-structure models depicting this region of the RNA as single stranded $(5,25,38)$. Since RNase $\mathrm{H}$ requires at least four base pairs for digestion (11), we conclude that residues 49 to 52 are accessible in the RNP, while residues $3^{\prime}$ of this region are not. In addition, the efficient cleavage by Oxy 38-68 and 42-62 suggested that much of the telomeric sequence was available for oligonucleotide binding.

In summary, the $O$. nova 190 RNA bears striking similarity to the previously characterized $E$. crassus telomerase RNA. 


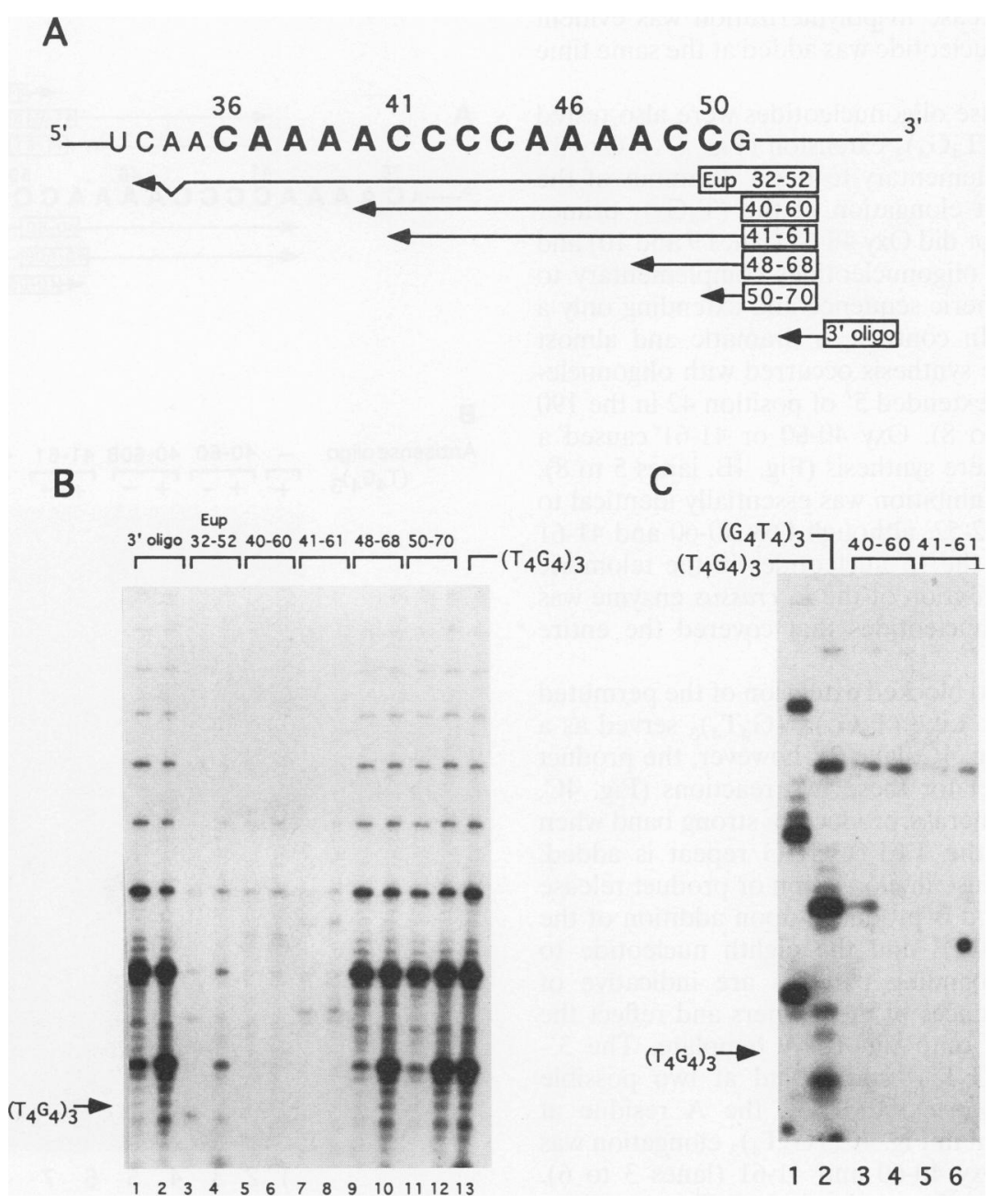

FIG. 4. Masking the telomeric sequence within the 190 RNA with antisense oligonucleotides. (A) Antisense oligonucleotides are as described for Fig. 3A. Eup 32-52 (5' GTTTGTTTTGGGGTTTTGGCT 3') has complete complementary to the $O$. nova 190 RNA telomeric sequence but not outside this domain, as indicated by the nonlinear arrow. All other antisense oligonucleotides are $O$. nova specific. (B and $\mathrm{C}$ ) Inhibition of the $O$. nova telomerase. Telomerase extracts were assayed for elongation of $\left(T_{4} G_{4}\right)_{3}(B)$ or $\left(G_{4} T_{4}\right)_{3}(C)$ in the presence of an antisense oligonucleotide. Reactions shown in odd-numbered lanes in panel $\mathrm{B}$ and lanes 3 and 5 in panel $\mathrm{C}$ had extract preincubated with the antisense oligonucleotide. Reactions shown in even-numbered lanes in panel $\mathrm{B}$ and lanes 4 and 6 in panel $\mathrm{C}$ had no preincubation step. Arrows indicate the position of plus-one $\left(\mathrm{T}_{4} \mathrm{G}_{4}\right)_{3}$ elongation products.

The RNA is approximately the same size and relative abundance and carries a sequence predicted to template the addition of TTTTGGGG repeats. Furthermore, the 190 RNA exists as an RNP complex with the telomeric sequence accessible to DNA binding. Given these properties, it seemed likely that the 190 RNA served as the telomerase RNA subunit for O. nova.

Masking the telomeric sequence within the $O$. nova 190 RNA blocks telomere synthesis in vitro. Confirmation that the 190 RNA provides the template for the $O$. nova telomerase was obtained by using antisense oligonucleotides to mask the telomeric sequence. The functional template for a telomerase RNA can be defined as the nucleotides that direct polymerization onto a primer $3^{\prime}$ end. Thus, the $O$. nova 190 RNA contains 15 nucleotides that could potentially serve as a template for synthesis of the eight-base TTTTGGGG repeat. If this domain is required for DNA synthesis, the binding of an oligonucleotide across it should inhibit polymerization. To achieve inhibition, the oligonucleotide would presumably need to be stably anchored over templating nucleotides in order to prevent elongation when challenged with a telomeric primer. Previous studies showed that the $E$. crassus telomerase is strongly inhibited by Eup 32-52, an antisense oligonucleotide that covers the entire telomeric sequence within the telomerase RNA. However, oligonucleotides that did not completely span this domain did not inhibit elongation (44). Since the $E$. crassus and $O$. nova RNAs have the same telomeric sequence, we tested whether Eup 32-52 would block elongation by the $O$. nova telomerase. Eup 32-52 has perfect complementarity to the $O$. nova 190 RNA across the telomeric sequence but not 5' or $3^{\prime}$ of this region (Fig. 4A). In the absence of Eup 32-52, the $O$. nova telomerase generated the characteristic TTTTGGGG repeated banding pattern as $\left[\alpha-{ }^{32} \mathrm{P}\right] \mathrm{dGTP}$ was incorporated upon extension of the $\left(\mathrm{T}_{4} \mathrm{G}_{4}\right)_{3}$ primer (Fig. 4B, lane 13). However, when an equimolar ratio of Eup 32-52 to $\left(\mathrm{T}_{4} \mathrm{G}_{4}\right)_{3}$ was included in the reaction, a striking decrease in primer elongation was observed. The inhibition was greater when Eup 32-52 was added before $\left(\mathrm{T}_{4} \mathrm{G}_{4}\right)_{3}$ (Fig. 4B, lane 3), al- 
though a substantial decrease in polymerization was evident when the antisense oligonucleotide was added at the same time (lane 4).

$O$. nova-specific antisense oligonucleotides were also tested for their ability to block $\left(\mathrm{T}_{4} \mathrm{G}_{4}\right)_{3}$ extension (Fig. 4A). Oxy $3^{\prime}$, the oligonucleotide complementary to the $3^{\prime}$ terminus of the 190 RNA, did not inhibit elongation of the $\left(\mathrm{T}_{4} \mathrm{G}_{4}\right)_{3}$ primer (Fig. 4B, lanes 1 and 2), nor did Oxy 48-68 (lanes 9 and 10) and 50-70 (lanes 11 and 12), oligonucleotides complementary to the region $3^{\prime}$ of the telomeric sequence and extending only a few nucleotides into it. In contrast, a dramatic and almost complete loss of telomere synthesis occurred with oligonucleotides whose $3^{\prime}$ terminus extended $5^{\prime}$ of position 42 in the 190 RNA (Fig. 4B, lanes 5 to 8 ). Oxy $40-60$ or $41-61$ caused a striking decrease in telomere synthesis (Fig. 4B, lanes 5 to 8 ). Surprisingly, the level of inhibition was essentially identical to that observed with Eup 32-52, although Oxy 40-60 and 41-61 covered only 10 or 11 of the 15 nucleotides in the telomeric sequence. In contrast, inhibition of the $E$. crassus enzyme was achieved only with oligonucleotides that covered the entire telomeric sequence (44).

Oxy 40-60 and 41-61 also blocked extension of the permuted telomeric primer $\left(\mathrm{G}_{4} \mathrm{~T}_{4}\right)_{3}$. Like $\left(\mathrm{T}_{4} \mathrm{G}_{4}\right)_{3},\left(\mathrm{G}_{4} \mathrm{~T}_{4}\right)_{3}$ served as a primer for telomerase (Fig. $4 \mathrm{C}$, lane 2); however, the product banding pattern was offset for these two reactions (Fig. $4 \mathrm{C}$, lane 1). The $O$. nova telomerase produces a strong band when the fourth $\mathrm{T}$ residue in the TTTTGGGG repeat is added, which corresponds to a pause in elongation or product release (49). Thus, an intense band is produced upon addition of the fourth nucleotide to $\left(\mathrm{T}_{4} \mathrm{G}_{4}\right)_{3}$ and the eighth nucleotide to $\left(G_{4} T_{4}\right)_{3}$. These distinct banding patterns are indicative of different 3 '-terminal sequences of the primers and reflect the unique primer alignment onto the RNA template. The $3^{\prime}-$ terminal $T$ residue of $\left(G_{4} T_{4}\right)_{3}$ could bind at two possible locations within the $O$. nova $190 \mathrm{RNA}$, the A residue at position 37 or 45 . As shown in Fig. $4 \mathrm{C},\left(\mathrm{G}_{4} \mathrm{~T}_{4}\right)_{3}$ elongation was strongly suppressed by Oxy 40-60 and 41-61 (lanes 3 to 6). These data suggest that the $3^{\prime}$ terminus of $\left(\mathrm{G}_{4} \mathrm{~T}_{4}\right)_{3}$ bound at position 45, since Oxy 40-60 and 41-61 cover this residue in the 190 RNA (Fig. 4A). The ability of Oxy 40-60 and 41-61 to block extension of both $\left(G_{4} T_{4}\right)_{3}$ and $\left(T_{4} G_{4}\right)_{3}$ is consistent with primer binding between positions 41 and 50 in the 190 RNA.

To further investigate inhibition by the antisense oligonucleotides, we tested whether hybridization outside the telomeric sequence in the 190 RNA was required to block polymerization. Oxy 40-60B and 41-61B are the same length as the original oligonucleotides and carry the same telomeric nucleotides on their $3^{\prime}$ termini. However, the $5^{\prime}$ ends of the B versions have been altered so that they are no longer complementary to the 190 RNA $3^{\prime}$ of the telomeric domain (Fig. 5A). Unlike reactions containing Oxy 40-60 and 41-61, $\left(\mathrm{T}_{4} \mathrm{G}_{4}\right)_{3}$ was elongated in the presence of 40-60B and 41-61B (Fig. 5B, lanes 4 and 8 ). Remarkably, the products generated with the Bversion oligonucleotides reached approximately the same length and intensity as in the controls lacking an antisense oligonucleotide (Fig. 5B, lane 1). In contrast to reactions with the original oligonucleotides (Fig. 5B, lanes 3 and 7), the $B$ versions of Oxy 40-60 and 41-61 served as extremely efficient primers for telomerase in the absence of $\left(\mathrm{T}_{4} \mathrm{G}_{4}\right)_{3}$ (Fig. 5B, lanes 5 and 9) and competed effectively with $\left(\mathrm{T}_{4} \mathrm{G}_{4}\right)_{3}$ for elongation when both were included in the same reaction. For example, the assay containing $40-60 \mathrm{~B}$ and $\left(\mathrm{T}_{4} \mathrm{G}_{4}\right)_{3}$ produced a mixed banding pattern of products corresponding to elongation of both oligonucleotides (Fig. 5B; compare lane 4 with lanes 1 and 5). The same result was obtained with Oxy 41-61B (Fig. 5B, lane 8). Thus, removing complementarity to the 190
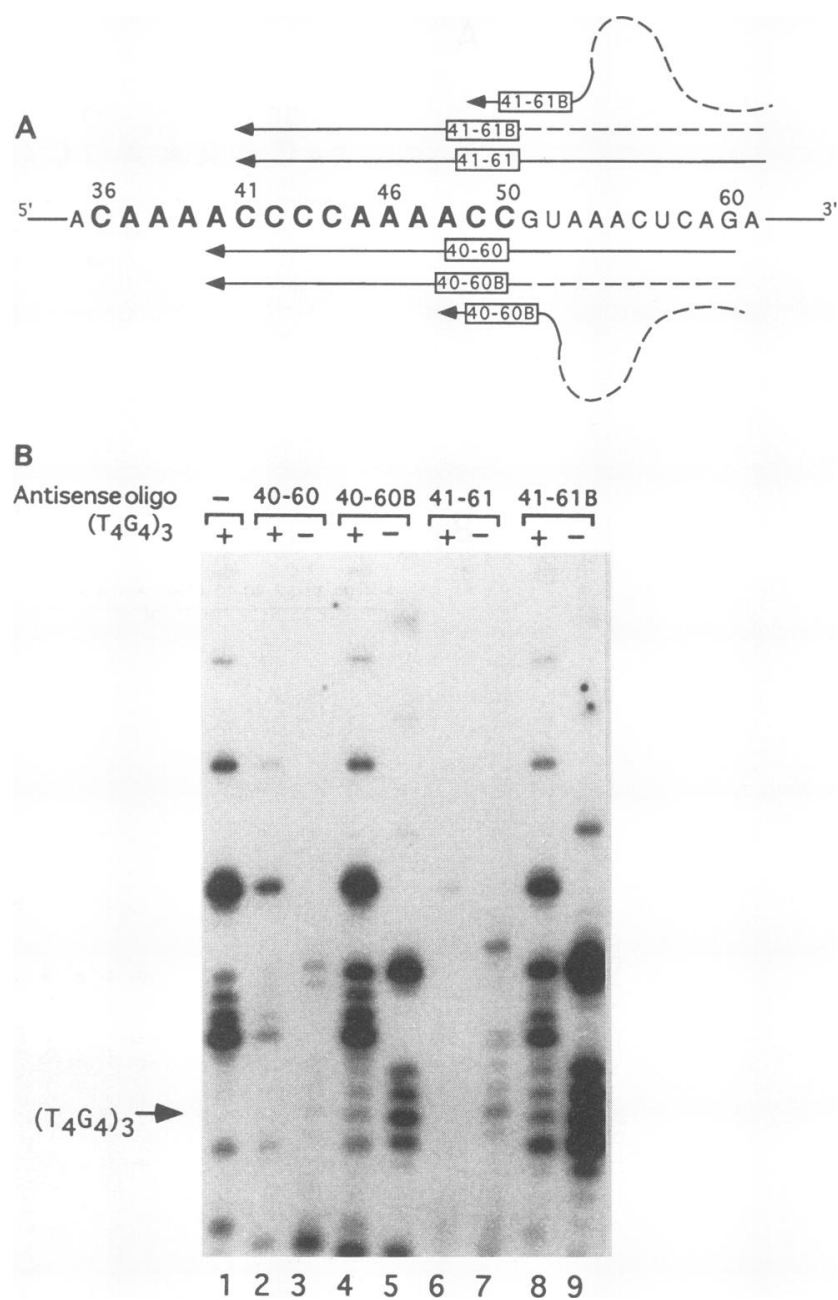

FIG. 5. Conversion of inhibitory oligonucleotides into telomerase primers. (A) The 5' ends of Oxy 40-60 and 41-61 were altered to eliminate complementarity to the 190 RNA $3^{\prime}$ of the telomeric sequence, producing Oxy 40-60B (5' GCAGTGGCAGGTTTTGG GGT $\left.3^{\prime}\right)$ and Oxy 41-61B (5' AAGCCTGCGGTGGTTTTGGGG $\left.3^{\prime}\right)$. Two possible binding positions for the B-version oligonucleotides are depicted. (B) Telomerase assays with Oxy 40-60, 41-61, and their B versions. Masking experiments are as described for Fig. 4 except that the antisense oligonucleotide was not preincubated with the extract. The arrow marks the position of the plus-one $\left(\mathrm{T}_{4} \mathrm{G}_{4}\right)_{3}$ product.

RNA 3' of the telomeric sequence radically altered the behavior of these oligonucleotides, not only ablating their ability to inhibit telomerase but also transforming them from poor into efficient primers.

The disparate behavior of Oxy 40-60 and 41-61 with their B versions provides strong evidence that the 190 RNA carries the template for telomere synthesis by the $O$. nova telomerase. Our data also suggested that the B-version $3^{\prime}$ termini were no longer binding at positions 40 and 41 the 190 RNA sequence. Rather, the oligonucleotides appeared to have aligned at residues 48 and 49 (Fig. 5A).

Antisense oligonucleotide primers delineate the boundaries of the $O$. nova telomerase RNA template. Previous studies with both the $T$. thermophila and $E$. crassus enzymes indicate that not all nucleotides in the telomere sequences are actually copied into DNA $(1,44)$. Some of these nucleotides appear to serve in alignment of the primer, positioning it correctly on the 
template, while others may simply lie outside the catalytic site. Since the $O$. nova and $E$. crassus telomerases generate the same repeat sequence, it was of interest to determine whether the corresponding nucleotides in each RNA served a template function. The ability of Oxy 40-60 and 41-61 to block telomere synthesis suggested that the template for the $O$. nova telomerase lay between positions 41 and 50 in the RNA. To investigate this possibility further, we tested the ability of antisense oligonucleotides to serve as telomerase primers. This approach assumes that oligonucleotides complementary to the telomerase RNA will prime telomere repeat synthesis if their $3^{\prime}$ termini are positioned adjacent to a template nucleotide (44).

Antisense oligonucleotides hybridizing distal to the telomeric domain such as Oxy $3^{\prime}$ or $5^{\prime}$ did not serve as primers for the $O$. nova telomerase (data not shown). In contrast, oligonucleotides that terminated within or $3^{\prime}$ adjacent to the telomeric sequence primed telomerase; however, the elongation profile varied dramatically, depending on the oligonucleotide $3^{\prime}$ terminus. The antisense oligonucleotide primers fell into three categories. Category 1 oligonucleotides were very poor primers, extended by the addition of no more than a single eight-base repeat; category 2 primers were exceptionally efficient primers, generating a massive accumulation of short products; category 3 primers generated a bimodal distribution of short and long products, with little to no intermediate-length molecules.

Category 1 oligonucleotides, such as Oxy 38-58 and 40-60, extended $5^{\prime}$ of position 42 in the 190 RNA and were very weak telomerase primers (Fig. 6B, lanes 2 and 3) compared with other antisense oligonucleotides (Fig. 6B, lanes 4 to 7 ) or the $\left(\mathrm{T}_{4} \mathrm{G}_{4}\right)_{3}$ control (Fig. 6B, lane 8 ). As described above, category 1 oligonucleotides also inhibit telomerase elongation. These two observations are consistent with the $3^{\prime}$ terminus of category 1 oligonucleotides binding primarily outside the functional template domain. Interestingly, the analogous oligonucleotides behaved as category 2 primers for the $E$. crassus enzyme (44) (see below).

A radically different elongation profile was obtained with oligonucleotides that terminated between residues 42 and 47 (category 2 primers). Although both intermediate and longer products were generated in these reactions, there was a massive buildup of short products corresponding to the addition of 8 to 12 nucleotides (Fig. 6B, lanes 4 to 6). When we quantitated the amount of radioactivity incorporated into the first repeat added to category 2 primers, we found 100 times more ${ }^{32} \mathrm{P}$ than in the $\left(\mathrm{T}_{4} \mathrm{G}_{4}\right)_{3}$ control reaction (not shown). An analogous product profile was obtained with $E$. crassus telomerase by using antisense oligonucleotides $(28,44)$. In our earlier study, it was suggested that the accumulation of short products was due to arrested elongation as the antisense primers became immobilized by binding to the telomerase RNA outside the template domain (44). To directly test this hypothesis, we altered the $5^{\prime}$ sequence of Oxy 44-64 so that it could no longer bind to the 190 RNA $3^{\prime}$ of the template domain (Fig. 7A). When this new oligonucleotide, Oxy 44-64B, was assayed for elongation, small products accumulated to approximately the same degree as in reactions with the original version (Fig. 7B; compare lanes 2 and 3). We observed the same result with the $E$. crassus telomerase when a corresponding primer was used (not shown). These data do not support the primer immobilization model for short-product accumulation.

Experiments with the Tetrahymena and human telomerases have demonstrated that telomeric sequences at the $5^{\prime}$ termini of primer molecules can influence both their recognition and elongation $(19,23,30)$. We investigated the role of $5^{\prime}$ residues
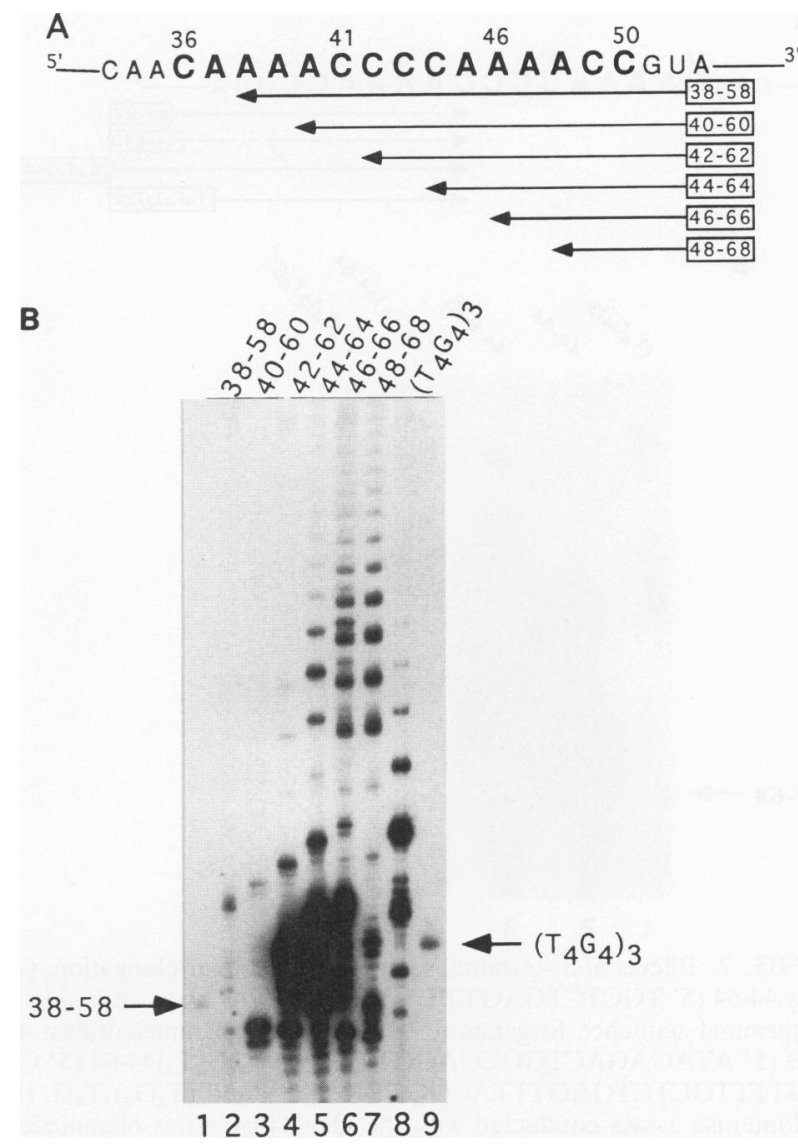

FIG. 6. Elongation of antisense oligonucleotides. (A) Antisense oligonucleotides used to prime telomerase. (B) Telomerase reactions were carried out with antisense oligonucleotides in the absence of telomeric primers. The plus-one products of Oxy 38-58 (lane 1) and $\left(\mathrm{T}_{4} \mathrm{G}_{4}\right)_{3}$ (lane 9) are indicated.

in the elongation of antisense oligonucleotides by adding GGGGTTTT onto the $5^{\prime}$ terminus of Oxy 44-64, now designated $\left(\mathrm{G}_{4} \mathrm{~T}_{4}\right)$ 44-64. A 29-mer, $\left(\mathrm{G}_{4} \mathrm{~T}_{4}\right) 44-64$, has 21 nucleotides of complementarity to the 190 RNA, and its $3^{\prime}$ terminus covers the same residues in the template domain as Oxy 44-64 and 44-64B (Fig. 7A). As shown in Fig. 7B, the $\left(\mathrm{G}_{4} \mathrm{~T}_{4}\right) 44-64$ short-product bands were much less intense (compare lane 4 with lanes 2 and 3) and incorporated approximately 10-fold less radioactivity into the first repeat than the 44-64 or 44-64B reaction (not shown). This new distribution of products most likely reflects an increase in processivity, since under our reaction conditions ( $>100$-fold excess primer over enzyme), primers once released are unlikely to reassociate with the enzyme.

Although the accumulation of small products was decreased with $\left(G_{4} T_{4}\right) 44-64$ relative to a primer lacking telomeric sequence at its $5^{\prime}$ end, the $\left(\mathrm{G}_{4} \mathrm{~T}_{4}\right)$ 44-64 reaction still incorporated about 10 times more ${ }^{32} \mathrm{P}$ than the $\left(\mathrm{T}_{4} \mathrm{G}_{4}\right)_{3}$ control (Fig. $7 \mathrm{~B}$; compare lane 4 with lane 1$)$. Since $\left(\mathrm{G}_{4} \mathrm{~T}_{4}\right) 44-64$ carries telomeric sequence on its $5^{\prime}$ and $3^{\prime}$ ends but not in the middle, we tested whether internal sequences within the primer influence elongation. $O$. nova telomerase assays were carried out with $\left(T_{4} G_{4}\right)_{2} T_{4} G$, a telomeric oligonucleotide of the same length and 3 -terminal sequence as 44-64 (Fig. 7A). Interestingly, this reaction generated short products of the same relative abundance as with $\left(\mathrm{G}_{4} \mathrm{~T}_{4}\right)$ 44-64 (Fig. 7B; compare lane 
A
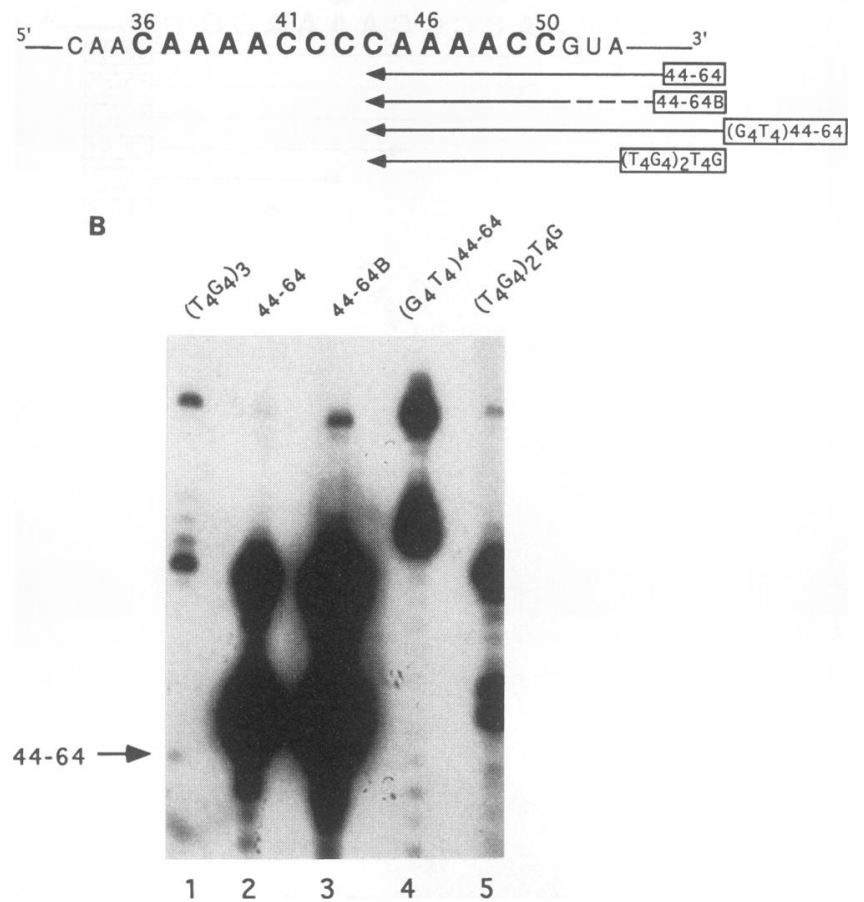

FIG. 7. Effects of $5^{\prime}$-terminal sequences on primer elongation. (A) Oxy 44-64 (5' TGCTCTGAGTTTACGGTTTTG $\left.3^{\prime}\right)$ was altered in its 5 '-terminal sequence to generate the following oligonucleotides: 4464B (5' ATAGAGACTGGCGAGGTTTTG 3'), $\left(\mathrm{G}_{4} \mathrm{~T}_{4}\right) 44-64$ (5' GG GGTTTTGCTCTGAGTTTACGGTTTTG $\left.3^{\prime}\right)$, and $\left(\mathrm{T}_{4} \mathrm{G}_{4}\right)_{2} \mathrm{~T}_{4} \mathrm{G}$. (B) Telomerase assays conducted with the Oxy 44-64 series oligonucleotides. Only the bottom portion of the gel is shown. The plus-one 44-64 product is indicated by the arrow.

4 with lane 5). No further reduction in small-product accumulation was detected. Thus, the mode of elongation with the $O$. nova telomerase was strongly influenced by the presence of telomeric sequences at both the $5^{\prime}$ and $3^{\prime}$ ends of a primer, while internal telomeric DNA had little effect.

Template-directed oligonucleotides carrying fewer than five telomeric nucleotides on their $3^{\prime}$ ends (terminating between residues 47 and 51 in the RNA) comprised category 3 antisense primers. Such primers were used at a somewhat lower efficiency than category 2 oligonucleotides, which terminate between positions 42 and 46 and have additional telomeric nucleotides on their $3^{\prime}$ ends. In contrast to category 1 and 2 primers, category 3 primers generated a striking bimodal size distribution of products, one population consisting of primers extended by the addition of a single repeat and a second population of longer molecules elongated by four or more repeats (Fig. 8B, lanes 6 to 9, and data not shown). There was a remarkable paucity of intermediate-length products. The short products were similar in both size and relative abundance to those obtained with category 1 primers, which extended $5^{\prime}$ of position 42 in the 190 RNA (Fig. 8B; compare lanes 3 to 5 with lanes 7 to 9 ).

As is typical for telomerase reactions, the banding pattern of the short products from category 1 and 3 primers was offset for each of the primers that we tested, reflecting the unique 3 '-terminal sequences of the oligonucleotides and their proper alignment onto the RNA template (Fig. $8 \mathrm{~A}$ and $\mathrm{B}$, lanes 2 to 5 and 7 to 9). Surprisingly, this was not the case with the higher-molecular-weight products synthesized in these same
A
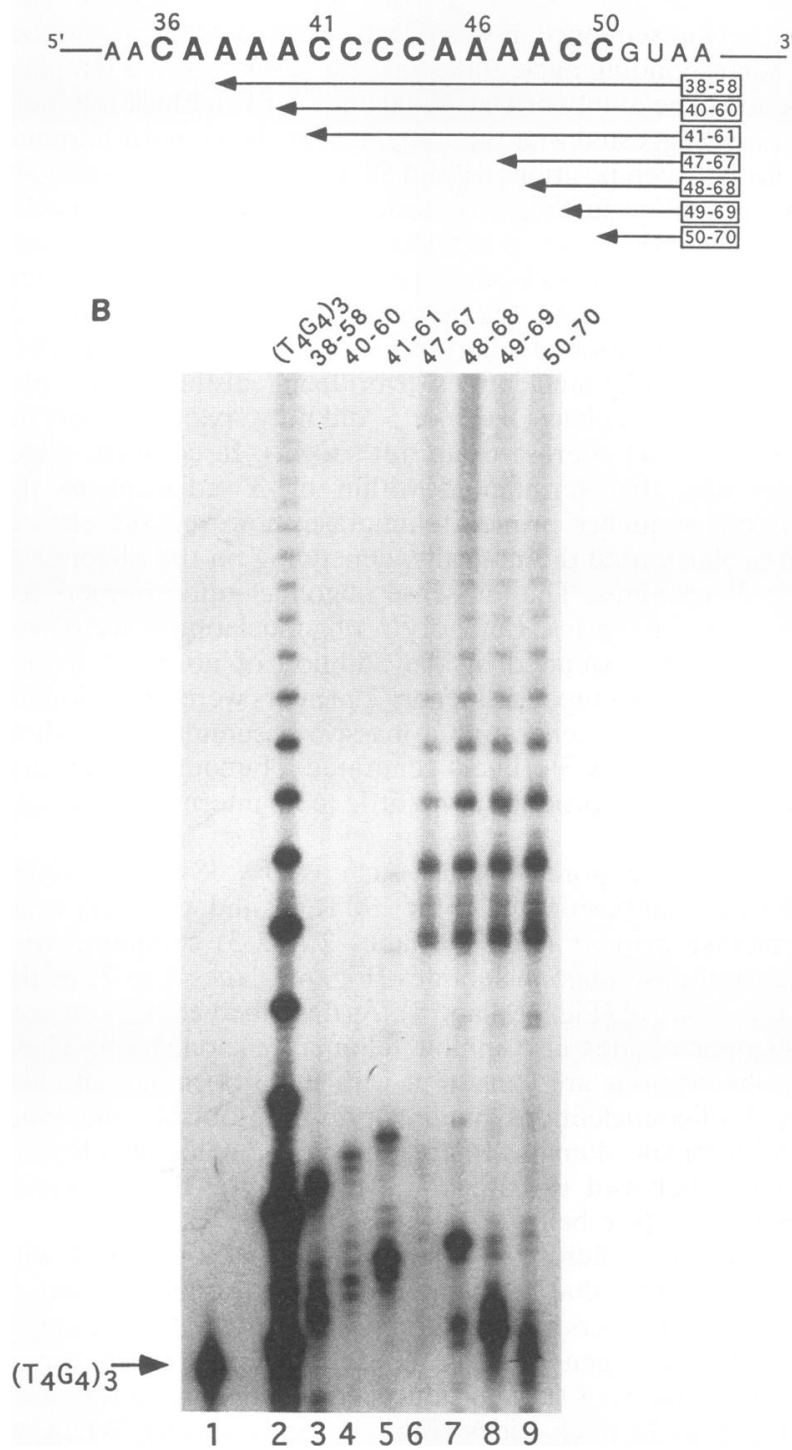

FIG. 8. Bimodal distribution of telomerase elongation products. (A) Antisense oligonucleotides used to prime telomerase. (B) Telomerase extracts were assayed with the antisense oligonucleotides shown. The $\gamma^{-32} \mathrm{P}-5^{\prime}$-end labeled $\left(\mathrm{T}_{4} \mathrm{G}_{4}\right)_{3}$ marker in lane 1 is indicated by the arrow. This gel was exposed to film three times longer $(72 \mathrm{~h})$ than gels shown in other figures.

reactions. Instead of an offset banding pattern, the longer products were absolutely uniform for all primers that terminated between residues 47 and 51, despite the different 3 'terminal sequences of these oligonucleotides (Fig. 8A and B, lanes 6 to 9 , and data not shown). In order to have acquired the same register of TTTTGGGG repeats, the longer products appeared to have been derived from primer molecules that aligned, in a sequence-independent manner, at a default position in the RNA template. Furthermore, the lack of intermediate-length products and the distinctive banding patterns of the small and long products indicated that two different types of primer elongation occurred in the same reaction.

Figure 9 summarizes the behavior of the antisense oligonucleotides in categories 1,2 , and 3 with respect to their ability to 
A

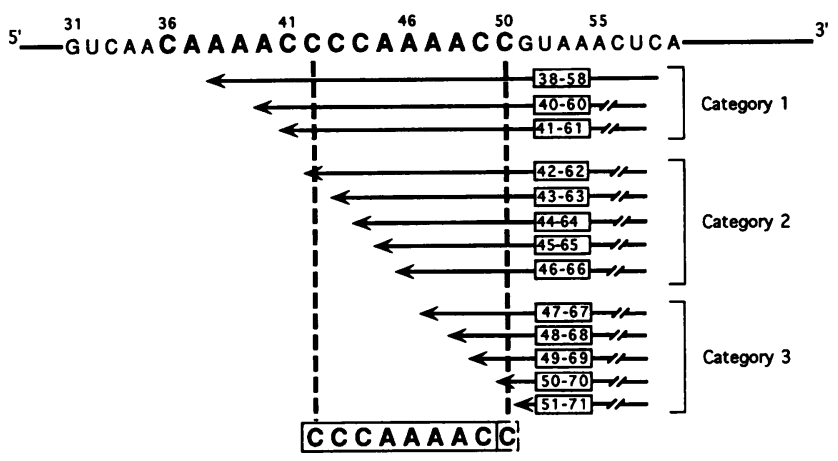

B

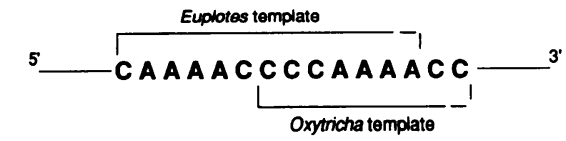

FIG. 9. Antisense oligonucleotides map the telomeric templates for the $O$. nova and E. crassus telomerase RNAs. (A) Antisense oligonucleotides were classified into three categories based on their ability to block elongation of telomeric primers and to serve as primers for the $O$. nova telomerase. Category 1 primers block extension of telomeric primers and are very poorly elongated. Category 2 primers are efficient telomerase primers but accumulate small products corresponding to the addition of one to two repeats. Category 3 primers display a bimodal distribution of short and long products. The long products do not appear to be derived from sequence-specific alignment on the RNA template (see text for details). Data for Oxy 43-63, 45-65, and 51-71 are not shown. Positions 42 to 49 are postulated to direct polymerization, while the $C$ residue at position 50 may serve to align the primer onto the template (dashed box). (B) Comparison of the templates for the $O$. nova and $E$. crassus telomerase RNAs. The dashed portion of the lines over the $E$. crassus telomeric sequence indicates a possible alignment nucleotide (44). The boundaries for both templates were mapped by using the strategy employed in this study.

block elongation of $\left(T_{4} G_{4}\right)_{3}$ and $\left(G_{4} T_{4}\right)_{3}$ and to act as primers for telomerase. Oligonucleotides terminating between residues 42 and 51 in the 190 RNA primed telomere addition, while those that extended $5^{\prime}$ of position 42 acted as potent telomerase inhibitors and were elongated very inefficiently. These data are consistent with position 42 marking the $5^{\prime}$ end of the functional template or the point of primer translocation between rounds of TTTTGGGG repeat synthesis.

\section{DISCUSSION}

The $O$. nova 190 RNA templates the addition of TTTTGGGG repeats. In many eukaryotes, synthesis of the G-rich telomeric DNA strand appears to proceed by a mechanism in which an essential RNA subunit of the telomerase RNP templates the addition of nucleotides onto the $3^{\prime}$ terminus of the chromosome end. Elucidating how telomerase recognizes and maintains telomeres is critical to understanding how the telomere mediates chromosome stability (26), prevents cell cycle arrest $(11,39)$, and facilitates proper nuclear and cellular division (48). At present, nothing is known about the protein components of telomerase. However, the RNA moiety has been isolated from several ciliated protozoa $(18,25,38,44)$, and characterization of this subunit greatly advanced our understanding of the mechanism of telomere synthesis. In this study, oligonucleotides complementary to the $O$. nova telomerase RNA template domain facilitated the identification of this molecule, delineated the functional boundaries of the template, and provided new insight into the mechanism of primer recognition and elongation.

The $O$. nova 190 RNA was identified by its hybridization to an oligonucleotide complementary to the predicted template domain. We suggest that this approach could be used to identify telomerase RNAs from other organisms. The 190 RNA bears a 15-nucleotide sequence complementary to its G-rich telomeric strand. Outside this domain, several patches of sequence identity to the $E$. crassus telomerase RNA are evident, including the four nucleotides just upstream of the telomeric sequence that are absolutely conserved among all the known telomerase RNAs $(37,38,44)$. As expected for a telomerase RNA, the 190 RNA is found in an RNP particle and the telomeric sequence is accessible for oligonucleotide binding. Oligonucleotide-directed RNase $\mathrm{H}$ cleavage experiments were used to examine the accessibility of the telomeric sequence within the particle. We showed that oligonucleotide binding in this region not only directs cleavage by RNase $\mathrm{H}$ but also inhibits elongation by the enzyme (see below). These findings are consistent with the current models for holotrichous and hypotrichous ciliate telomerase RNA secondary structure which depict the template and surrounding nucleotides as single stranded $(5,25,38)$. Interestingly, the four conserved residues just $5^{\prime}$ of the telomeric sequence did not appear to be as accessible to RNase $\mathrm{H}$ cleavage. However, treatment with chemical probes such as dimethyl sulfate will be needed to accurately gauge the accessibility of the telomerase RNA within its RNP particle. Our $O$. nova 190 RNA sequence data are identical to those independently obtained by Lingner et al. (25). Sequencing telomerase RNAs from a variety of hypotrichous ciliates, these authors show that the $O$. nova and E. crassus telomerase RNAs conform to the secondary-structure model originally proposed for the tetrahymenine group ciliates $(5,38)$. Thus, despite the rather divergent nucleotide sequences of telomerase RNAs, these molecules appear to assume similar secondary structures.

Using antisense oligonucleotides to mask the telomeric sequence within the 190 RNA, we demonstrated that this domain was required for polymerization by the $O$. nova telomerase. Surprisingly, an oligonucleotide that covers 10 of the 15 nucleotides in the telomeric sequence (Oxy 41-61) was sufficient to block elongation of both $\left(\mathrm{T}_{4} \mathrm{G}_{4}\right)_{3}$ and $\left(\mathrm{G}_{4} \mathrm{~T}_{4}\right)_{3}$. This finding demonstrates that the 190 RNA provides the template for the $O$. nova telomerase. In addition, the ability to inhibit elongation of $\left(\mathrm{T}_{4} \mathrm{G}_{4}\right)_{3}$ and $\left(\mathrm{G}_{4} \mathrm{~T}_{4}\right)_{3}$ by covering residues 42 to 50 in the $O$. nova RNA sequence suggests that the binding sites for these two oligonucleotides lie between these residues.

To obtain telomerase inhibition, the antisense oligonucleotides needed complementarity to the telomerase RNA in the region $3^{\prime}$ of the telomeric sequence. The B versions of Oxy 40-60 and 41-61, which cannot bind the 190 RNA outside the telomeric sequence, do not inhibit telomerase. We postulate that the reduced complementarity affords the B-version oligonucleotides greater flexibility in binding to the telomerase RNA, permitting their $3^{\prime}$ termini to align at residue 48 or 49 (within the functional template domain), as opposed to positions 40 and 41 (outside the functional template) (see below). This positioning not only would allow the B-version oligonucleotides to be extended by telomerase but also would provide $\left(T_{4} G_{4}\right)_{3}$ and $\left(G_{4} T_{4}\right)_{3}$ access to the template. On the basis of this reasoning, it seems likely that the small amount of extension we observed with antisense oligonucleotides that 
extend $5^{\prime}$ of residue 42 was due to a minor population of molecules whose $3^{\prime}$ termini manage to align within the functional template domain.

$O$. nova and $E$. crassus use different sets of nucleotides to synthesize TTTTGGGG repeats. Our data uncover a fundamental difference in the behavior of the $O$. nova and $E$. crassus telomerases. Although both enzymes synthesize the same TTTTGGGG repeat and carry identical telomeric sequences within their RNA subunits, they do not respond in the same manner to the corresponding antisense oligonucleotides. Under the same reaction conditions, oligonucleotides that block elongation by the $O$. nova telomerase serve as efficient primers for the $E$. crassus enzyme $(28,44)$. These and other data indicate the two polymerases use different sets of nucleotides within the telomerase RNA to synthesize TTTTGGGG repeats (Fig. 9). If this is so, then the enzyme-active sites in the $O$. nova and $E$. crassus telomerases are grossly offset with respect to the RNA subunit of the enzyme.

Several lines of evidence support the contention that residues 42 to 50 provide the template for TTTTGGGG repeat synthesis by the $O$. nova telomerase. First, telomerase elongation is blocked by oligonucleotides that cover positions 42 to 50 in the RNA. Although such oligonucleotides can prime telomere extension, the length and abundance of the products are very low. Second, changing the 3 '-terminal sequence of a complementary oligonucleotide by one nucleotide so that it can pair with residue 42 instead of residue 41 dramatically alters its effect on telomerase, converting it from an inhibitor to an extremely efficient primer.

Inspection of the profile of reaction products generated by telomerase has been used to infer the position of the $5^{\prime}$ boundary of the template. Indeed, the most intense band in the Tetrahymena telomerase product profile reflects copying the 5 '-most nucleotide in the template domain and corresponds to primer translocation and/or product release $(1,16)$. By contrast, the $E$. crassus telomerase produces two strong bands with antisense oligonucleotide primers, one interpreted as translocation after copying the $5^{\prime}$ end of the template and a second which corresponds to an internal location within the template domain $(43,44)$. Interestingly, copying at this internal location produces the most intense band with standard telomeric primers $(4,43,44)$. The $O$. nova telomerase appears to be more like the $E$. crassus enzyme in this regard. Products terminating upon the addition of the fourth $T$ residue accumulate with standard telomeric primers $(28,49)$, while an additional strong band corresponding to copying the $\mathrm{C}$ at position 42 (our $5^{\prime}$ boundary placement) is obtained with antisense oligonucleotides (28). The molecular basis for the different product profiles obtained with the Tetrahymena and hypotrichous ciliate telomerases and their relationship to copying specific residues within the RNA templates is unclear. However, on the basis of the cumulative data obtained with the antisense oligonucleotides, we propose that the template for the $O$. nova telomerase encompasses residues 42 to 50 .

Our model for the $O$. nova template domain indicates that residue 42 is the last nucleotide copied into DNA before the primer is translocated and realigned on the template. Since an eight-nucleotide repeat is synthesized by this enzyme, we postulate that the $\mathrm{C}$ residue at position 50 does not direct polymerization but rather serves to realign the primer onto the active site after each elongation cycle. Alteration of a single nucleotide dramatically affects primer alignment, as judged from site-directed mutagenesis experiments with the Tetrahymena telomerase RNA (1).

Finally, it should be noted that our mapping of the template boundaries for the $O$. nova telomerase represents an opera- tional definition. Precise delineation will require the use of strategies such as those employed with the Tetrahymena telomerase RNA. The boundaries of this template domain have been delineated by transformation of mutant telomerase RNA genes in vivo and by reconstitution of telomerase activity with mutant telomerase RNAs in vitro $(1,48)$. Although neither of these technologies is currently available for the hypotrichous ciliates, a number of laboratories, including our own, are actively pursuing these goals.

Primer recognition and elongation by the $O$. nova telomerase. Our experiments with antisense oligonucleotides provide new information on the mechanism of primer recognition and elongation by telomerase. We found that oligonucleotides carrying fewer than five nucleotides of telomeric sequence at their $3^{\prime}$ termini can prime the $O$. nova telomerase, although somewhat less efficiently than standard telomeric primers or antisense oligonucleotides with more telomeric sequence. Such reactions present a striking bimodal size distribution of short (one repeat added) and long (more than four repeats) products. Surprisingly, almost no molecules terminating upon the addition of two to four TTTTGGGG repeats are synthesized. Although the battery of primers tested had different $3^{\prime}$ terminal sequences, only the short products display the typical offset banding profile characteristic of sequence-specific primer alignment onto the template. In contrast, the banding pattern of the higher-molecular-weight products is in identical register for all primers tested.

The simplest explanation for the bimodal product distribution is two separate elongation events. We postulate that the short products are generated by oligonucleotide release (product turnover) (see below). The mechanism responsible for synthesis of the longer products is less clear. One intriguing possibility is that primers with little to no telomeric sequence on their $3^{\prime}$ termini can be directed to a default alignment position on the RNA template. Recent experiments with the $E$. crassus telomerase indicate that this enzyme also extends primers lacking 3 '-terminal telomeric sequence by adding the same register of TTTTGGGG repeats (28). Although we do not yet know the precise sequence added to such primers, these experiments are currently under way. The Tetrahymena and human telomerases are known to extend primer $3^{\prime}$ termini that are mismatched onto the RNA template $(19,30)$, but ours are the first data to suggest that nontelomeric $3^{\prime}$ ends may be processed in a highly regulated manner by telomerase. The ability of telomerase to add the same nucleotides to different $3^{\prime}$ ends could be an important property of this polymerase and may explain why the register of telomeric repeats added during de novo telomere formation in $E$. crassus and $O$. nova is invariant despite the wide variety of telomere addition site sequences (21). This finding may also have implications for the spontaneous chromosome healing events observed in higher eukaryotes (references 19 and 30 and references therein).

With several of the antisense primers (category 2), the $O$. nova telomerase generated a massive accumulation of short products corresponding to the addition of two or fewer TTT TGGGG repeats. When the analogous elongation pattern was produced by the $E$. crassus enzyme, it was postulated that hybridization to the RNA $3^{\prime}$ of the template domain arrested elongation and caused a buildup of short products (44). An alternative explanation is that the short-product accumulation reflects turnover or oligonucleotide release. Several lines of evidence support the latter conclusion. First, decreasing complementarity of the primer to the telomerase RNA did not diminish the abundance of small products. B-version oligonucleotides accumulated as much or more short products as the original versions, which carried extended complementarity 
outside the template domain. Second, the only oligonucleotides that appeared to be immobilized onto the RNA are those that bind both $5^{\prime}$ and $3^{\prime}$ of the functional template (category 1 ); these oligonucleotides were potent inhibitors of elongation when the enzyme was challenged with a standard telomeric primer. Unlike category 2 primers, category 1 oligonucleotides served as extremely inefficient primers for telomerase. Third, when complementarity outside the template domain was eliminated, category 1 oligonucleotides were converted into category 2 , and they accumulated a large amount of short products. Thus, the degree of complementarity to the telomerase RNA does not correlate with the level of small-product accumulation. Finally, preliminary experiments comparing the relative number of enzyme molecules (telomerase RNA levels) versus the abundance of short products generated in category 2 primer reactions reveal product turnover by the $E$. crassus telomerase (28). Similar experiments are currently under way with the $O$. nova telomerase.

Taken together, the data presented here support a model for telomerase elongation that resembles the "inchworm" mechanism proposed for RNA polymerase (RNAP) elongation (7, $20,22,31)$. In this model, RNAP elongation is mediated by the binding of RNA transcripts to two sites on the polymerase (leading and lagging sites), each holding approximately nine nucleotides $(7,22)$. The $3^{\prime}$ terminus of the RNA binds loosely to the leading site and may form as few as two to three base pairs with the DNA template (36). This unstable association of the nascent transcript with RNAP has been invoked to explain the premature release of products shorter than nine nucleotides in abortive initiation $(7,10)$. RNA elongation proceeds in two distinct phases as RNAP alternatively fills the leading site by nucleotide addition and then, in the second phase, threads the transcript into the lagging site, where it becomes stably anchored. During this translocation step, RNAP snaps forward on the DNA template, leaving the leading site empty once again and ready for a second round of nucleotide addition (7, $20,22,31,36$ ). The passage of RNA through the lagging site presumably allows subsequent processive elongation (20).

Like RNAP, telomerase appears to contain two binding sites, the template and anchor sites (9). Originally postulated to account for extension of primers that lacked telomeric sequences at their $3^{\prime}$ ends $(19,30)$, the telomerase anchor site interacts with telomeric sequences distal to the $3^{\prime}$ terminus to increase processivity $(19,23,24,30)$. Our data provide strong support for this model. The majority of elongation products generated with primers bearing little telomeric sequence on their $3^{\prime}$ termini (all of the antisense primers examined in this study) reflect the addition of fewer than 12 nucleotides. The most intense bands in the product profile correspond to the first and second rounds of extension out to the end of the functional template, consistent with product release at or before the first two translocation steps. Oligonucleotides with only a few nucleotides of telomeric sequence at their $3^{\prime}$ ends may be recognized by telomerase in much the same way as short oligonucleotides that are completely telomeric. Nonprocessive elongation has been reported for the Tetrahymena telomerase $(9,23)$ and appears to correlate with primer length (23). We postulate that short telomeric primers or primers carrying insufficient telomeric sequence at the $3^{\prime}$ terminus cannot stably associate with the telomerase anchor site, and thus productive polymerization on the template as well as primer translocation are inhibited. This conclusion is supported by our ability to drastically reduce small-product accumulation by adding a telomeric repeat onto the $5^{\prime}$ terminus of an antisense oligonucleotide. Presumably, the additional telo- meric sequence strengthens binding to the anchor site and facilitates more processive elongation.

Further experimentation will obviously be needed to evaluate the two-primer-binding-site model for telomerase. However, our data suggest that the telomerase elongation mechanism may parallel that of RNAP. Given the wealth of information available on RNAP, this paradigm will likely provide a useful framework for directing further biochemical investigations of the telomerase enzyme.

\section{ACKNOWLEDGMENTS}

We are indebted to Carolyn Price and David Prescott for providing $O$. nova macronuclei and cells and for helpful advice on cell culturing. We also thank Jan Engberg for his advice on reverse transcriptase sequencing, Ruth White for expert technical assistance, and Joachim Lingner and Tom Cech for communicating results prior to publication. Diane Hawley, Jeff Kapler, and our colleagues at Texas A\&M University provided many insightful comments.

This work was supported by NIH grant GM49157 and American Cancer Society Junior Faculty Research Award JFRA-468 to D.E.S.

\section{ADDENDUM IN PROOF}

Lingner et al. have also explored the boundaries of the $O$. nova telomerase RNA template domain using an approach similar to ours. However, their reaction conditions were somewhat different (nanomolar antisense oligonucleotide concentrations and 30 -min reactions at $\left.25^{\circ} \mathrm{C}\right)(25)$.

\section{REFERENCES}

1. Autexier, C., and C. W. Greider. 1994. Functional reconstitution of wild-type and mutant Tetrahymena telomerase. Genes Dev. 8:563575.

2. Avilion, A. A., L. A. Harrington, and C. W. Greider. 1992. Tetrahymena telomerase RNA levels increase during macronuclear development. Dev. Genet. 13:80-86.

3. Balakrishnan, R., M. Frolich, P. T. Rahaim, K. Bachman, and R. R. Yocum. 1993. Cloning and sequence of the gene encoding enzyme E-1 from the methionine salvage pathway of Klebsiella oxytoca. J. Biol. Chem. 268:24792-24795.

4. Bendeneko, J., and D. E. Shippen. Unpublished data.

5. Bhattacharyya, A., and E. H. Blackburn. Architecture of telomerase RNAs. EMBO J., in press.

6. Blackburn, E. H. 1992. Telomerases. Annu. Rev. Biochem. 61: 113-129.

7. Burukhov, S., V. Sagitov, and A. Goldfarb. 1993. Transcript cleavage factors from E. coli. Cell 72:459-466.

8. Chomczynski, P., and N. Sacchi. 1987. Single-step method of RNA isolation by acid guanidinium thiocyanate-phenol-choloroform extraction. Anal. Biochem. 162:156-159.

9. Collins, K., and C. W. Greider. 1993. Tetrahymena telomerase catalyzes nucleolytic cleavage and nonprocessive elongation. Genes Dev. 7:1364-1376.

10. Das, A. 1993. Control of transcription termination by RNAbinding proteins. Annu. Rev. Biochem. 62:893-930.

11. de Lange, T. 1994. Activation of telomerase in a human tumor. Proc. Natl. Acad. Sci. USA 91:2882-2885.

12. Donis-Keller, H. 1979. Site-specific enzymatic cleavage of RNA. Nucleic Acids Res. 7:179-192.

13. England, T. E., R. I. Gumport, and O. C. Uhlenbeck. 1977. Dinucleoside pyrophoshates are substrates for T4-induced RNA ligase. Proc. Natl. Acad. Sci. USA 74:4839-4842.

14. Fang, G., J. T. Gray, and T. R. Cech. 1993. Oxytricha telomerebinding protein: separable DNA-binding and dimerization domains of the $\alpha$-subunit. Genes Dev. 7:870-882.

15. Gottschling, D. E., and V. A. Zakian. 1986. Telomere proteins: specific recognition and protection of the natural termini of Oxytricha macronuclear DNA. Cell 47:195-205.

16. Greider, C. W. 1991. Telomerase is processive. Mol. Cell. Biol. 11: $4572-4580$. 
17. Greider, C. W., and E. H. Blackburn. 1985. Identification of a specific telomere terminal transferase activity in Tetrahymena extracts. Cell 43:405-413.

18. Greider, C. W., and E. H. Blackburn. 1989. A telomeric sequence in the RNA of Tetrahymena telomerase required for telomere repeat syntheses. Nature (London) 337:331-337.

19. Harrington, L., and C. W. Greider. 1991. Telomerase primer specificity and chromosome healing. Nature (London) 353:451453.

20. Johnson, T. L., and M. J. Chamberlin. 1994. Complexes of yeast RNA polymerase II and RNA are substrates for TFIIS-induced RNA cleavage. Cell 77:217-224.

21. Klobutcher, L. A., M. T. Swanton, O. Donini, and D. M. Prescott. 1981. All gene-sized DNA molecules in four species of hypotrichs have the same terminal sequence and an unusual $3^{\prime}$ terminus. Proc. Natl. Acad. Sci. USA 78:3015-3019.

22. Krummel, B., and M. J. Chamberlin. 1992. Structural analysis of ternary complexes of Escherichia coli RNA polymerase. Individual complexes halted along different transcription units have distinct and unexpected biochemical properties. J. Mol. Biol. 225:221-234.

23. Lee, M., and E. H. Blackburn. 1993. Sequence-specific DNA primer effects on telomerase polymerization activity. Mol. Cell. Biol. 13:6586-6599.

24. Lee, M. S., R. C. Gallagher, J. Bradley, and E. H. Blackburn. In vivo and in vitro studies of telomeres and telomerase. Cold Spring Harbor Symp. Quant. Biol., in press.

25. Lingner, J., L. L. Hendrick, and T. R. Cech. 1994. Telomerase RNAs of different ciliates have a common secondary structure and a permuted template. Genes Dev. 8:1994-1998.

26. Lundblad, V., and J. W. Szostak. 1989. A mutant with a defect in telomere elongation leads to senescence in yeast. Cell 57:633-643.

27. Mantell, L. L., and C. W. Greider. 1994. Telomerase activity in germline and embryonic cells of Xenopus. EMBO J. 13:3211-3217.

28. Melek, M., and D. E. Shippen. Unpublished data.

29. Morin, G. B. 1989. The human telomere terminal transferase enzyme is ribonucleoprotein that synthesizes TTAGGG repeats. Cell 59:521-529.

30. Morin, G. B. 1991. Recognition of a chromosome truncation site associated with alpha-thalassemia by human telomerase. Nature (London) 353:454-456.

31. Nudler, E., A. Goldfarb, and M. Kashlev. 1994. Discontinuous mechanism of transcription elongation. Science 265:793-796.

32. Ørum, H., H. Nielsen, and J. Engberg. 1991. Spliceosomal small nuclear RNAs of Tetrahymena thermophila and some possible snRNA-snRNA base-pairing interactions. J. Mol. Biol. 222:219232.
33. Peattie, D. 1979. Direct chemical method for sequencing RNA. Proc. Natl. Acad. Sci. USA 76:1760-1764.

34. Price, C. M. 1990. Telomere structure in Euplotes crassus: characterization of DNA-protein interactions and isolation of a telomere-binding protein. Mol. Cell. Biol. 10:3421-3431.

35. Prowse, K. R., A. A. Avilion, and C. W. Greider. 1993. Identification of a nonprocessive telomerase activity from mouse cells. Proc. Natl. Acad. Sci. USA 90:1493-1497.

36. Rice, G., M. J. Chamberlin, and C. M. Kane. 1993. Contacts between mammalian RNA polymerase II and the template DNA in a ternary elongation complex. Nucleic Acids Res. 21:113-118.

37. Romero, D. 1994. Personal communication.

38. Romero, D. P., and E. H. Blackburn. 1991. A conserved secondary structure for telomerase RNA. Cell 67:343-353.

39. Sandell, L. L., and V. A. Zakian. 1993. Loss of a yeast telomere: arrest, recovery, and chromosome loss. Cell 75:729-739.

40. Shippen, D. E. Unpublished data.

41. Shippen, D. E. 1993. Telomeres and telomerases. Curr. Opin Genet. Dev. 3:759-763.

42. Shippen, D. E., E. H. Blackburn, and C. M. Price. 1994. DNA bound by the telomere protein is accessible to telomerase and other DNA polymerases. Proc. Natl. Acad. Sci. USA 91:405-409.

43. Shippen-Lentz, D., and E. H. Blackburn. 1989. Telomere terminal transferase activity from Euplotes crassus adds large numbers of TTTTGGGG repeats onto telomeric primers. Mol. Cell. Biol. 9:2762-2764

44. Shippen-Lentz, D., and E. H. Blackburn. 1990. Functional evidence for an RNA template in telomerase. Science 247:546-552.

45. Watson, J. D. 1972. Origin of concatemeric T4 DNA. Nature (London) New Biol. 239:197-201.

46. White, E. M., D. L. Shapiro, C. D. Allis, and M. A. Gorovsky. 1988 Sequence and properties of the message encoding Tetrahymena $\mathrm{hv1}$, a highly evolutionarily conserved histone $\mathrm{H} 2 \mathrm{~A}$ variant that is associated with active genes. Nucleic Acids Res. 16:179-198.

47. White, R. A., and D. E. Shippen. Unpublished data.

48. Yu, G., J. D. Bradley, L. D. Attardi, and E. H. Blackburn. 1990. In vivo alteration of telomere sequences and senescence caused by mutated Tetrahymena telomerase RNAs. Nature (London) 344: 126-132.

49. Zahler, A. M., and D. M. Prescott. 1988. Telomere terminal transferase activity in the hypotrichous ciliate Oxytricha nova and a model for replication of the ends of linear DNA molecules. Nucleic Acids Res. 16:6953-6972.

50. Zakian, V. A. 1989. Structures and function of telomeres. Annu. Rev. Genet. 23:579-604. 